\title{
Synthesis, Thermodynamics Stability Constant and Relaxation Properties of Neutral Gd(III) Complex with Derivative from Diethylene Triamine Pentaacetic Acid and $p$-Hydroxybenzoyl Hydrazine
}

\author{
Ding-Wa Zhang, Zheng-Yin YANG, * Shi-Ping ZHANG, and Ru-Dong Yang \\ State Key Laboratory of Applied Organic Chemistry, College of Chemistry and Chemical Engineering Lanzhou University; \\ Lanzhou, Gansu, 730000, P.R. China. Received November 6, 2005; accepted December 2, 2005
}

A novel ligand, diethylenetriamine- $N, N^{\prime \prime}$-bis(acetyl-p-hydroxybenzoyl hydrazine)- $N, N^{\prime}, N^{\prime \prime}$-triacetic acid $\left(\mathrm{H}_{3} \mathrm{~L}\right)$ was synthesized and characterized on the basis of elemental analysis, molar conductivity, ${ }^{1} \mathrm{H}-\mathrm{NMR}$ spectrum, FAB-MS, TG-DTA analysis and IR spectrum. Its complex of Gd(III) holding promise of magnetic resonance imaging (MRI) was synthesized, and relaxivity $\left(R_{1}\right)$ of complex and Gd(DTPA $)^{2-}$ used as a control was determined in water solution, respectively. The relaxivity of $\mathrm{GdL}\left(R_{1}=6.391 \cdot \mathrm{mmol}^{-1} \cdot \mathrm{s}^{-1}\right)$ was larger than that of $\operatorname{Gd}(\mathrm{DTPA})^{2-}\left(R_{1}=4.34 \mathrm{l} \cdot \mathrm{mmol}^{-1} \cdot \mathrm{s}^{-1}\right)$. The relaxivity of GdL has also been investigated in human serum albumin (HSA) solution, the relaxivity of $\mathrm{GdL}$ was enhanced from $6.391 \cdot \mathrm{mmol}^{-1} \cdot \mathrm{s}^{-1}$ in water solution to $7.691 \cdot \mathrm{mmol}^{-1} \cdot \mathrm{s}^{-1}$ in HSA solution. In addition, thermodynamics stability constant of GdL was determined. The results showed that complex of GdL is a prospective MRI contrast agent, although the thermodynamic stability constant of GdL complex $\left(K_{\mathrm{GdL}}=10^{19.56}\right)$ was a little less than that of $\mathrm{Gd}(\mathrm{DTPA})^{2-}\left(K_{\mathrm{Gd}-\mathrm{DTPA}}=10^{20.73}\right)$.

Key words relaxation property; human serum albumin (HSA); thermodynamics stability constant; diethylenetriamine- $N, N^{\prime \prime}$ bis(acetyl-p-hydroxybenzoyl hydrazine)- $N, N^{\prime}, N^{\prime \prime}$-triacetic acid; MRI contrast agent

Magnetic resonance imaging (MRI) is at present well established as a safe and efficient imaging technique for the human body in clinical diagnosis. ${ }^{1)}$ Therefore, studying MRI contrast agents is more important. Several types of paramagnetic metal ion-chelate complexes with various ligands have been proposed for use as contrast-enhancing agents in MRI. ${ }^{1-3)}$ Gd(DTPA) ${ }^{2-}$ was well-established contrast agent in clinical use for MRI due to its high relaxivity, high chemical stability and low toxicity. ${ }^{3)}$ However, its passive and nonspecific distribution in vivo limits its utility in focal lesion detection and, moreover, its ionic characteristic leads to some side effects associated with its hyperosmolality at clinical dose. ${ }^{1,4)}$ In attempts to decrease the side effects and improve the tissue- and/or organ-specificity, considering that $p$-hydroxybenzoyl hydrazine molecule holds a hydroxyl which can enhance affinity to water and hydrazide is a very useful medicament that we designed and synthesized a novel ligand from DTPA and $p$-hydroxybenzoyl hydrazine. Its complex of $\mathrm{Gd}$ (III) holding promise of magnetic resonance imaging (MRI) was synthesized, and relaxivity of complex and Gd(DTPA) ${ }^{2-}$ was determined in water solution. The relaxivity of GdL has also been investigated in human serum albumin (HSA) solution. In addition, thermodynamics stability constant of GdL was determined. The results showed that GdL is a prospective MRI contrast agent.

\section{Experimental}

Materials HSA was purchased from Sigma Chemical Co. and was used without any further purification. $\mathrm{Gd}_{2}\left(\mathrm{CO}_{3}\right)_{3}$ was purchased from Shanghai Yuelong Chemical Works. DTPA, EDTA and $p$-hydroxybenzoyl hydrazine were purchased from Shanghai Reagent Factory. All other chemicals used were of analytical grade.

Measurements Carbon, hydrogen, and nitrogen were analyzed on an Elemental Vario EL analyzer. The metal content of the complex was determined by titration with EDTA. Melting points of the compounds were determined on an XT4-100x microscopic melting point apparatus (Beijing Electrooptical Instrument Factory, China). IR spectra were obtained in $\mathrm{KBr}$ discs on a Nicolet 5-DX spectrometer in the $4000-400 \mathrm{~cm}^{-1}$ region. ${ }^{1} \mathrm{H}-\mathrm{NMR}$ spectrum was recorded on a Varian VR 300-MHz spectrometer. Conductiv- ity measurement was performed in DMF with a DDS-11A conductometer at $25^{\circ} \mathrm{C}$ (Shanghai Jingke Instrument Factory, China).The thermal behavior was monitored on a PCT-2 differential thermal analyzer (Beijing Guangxue Instrument Factory, China). Mass spectrum was performed on a VG ZABHS (FAB) instrument.

Relaxation time of $\mathrm{Gd}(\mathrm{III}) \mathrm{L}$ complex was measured referring to literature $^{5)}$ by an inversion-recovery pulse sequence on a Bruker AC-80 NMR spectrophotometer, using the INVREC Au program at a $90^{\circ}$ pulse width $t_{\mathrm{p}}$ $\left(90^{\circ}\right)=2.8 \mu \mathrm{s}$

Thermodynamics stability constant of $\mathrm{Gd}(\mathrm{III}) \mathrm{L}$ complex was measured referring to literature ${ }^{6}$ by potentiometric measurement $\left(T=25^{\circ} \mathrm{C}, 0.10 \mathrm{~mol} / 1\right.$ $\mathrm{NaCl})$.

Preparation of Ligand The synthetic routes of ligand and complex were showed in Fig. 1. Ligand was synthesized as following:

Diethylenetriamine pentaacetic bi-anhydride (DTPAA) has been prepared according to references. ${ }^{7,8)}$

$2 \mathrm{mmol}$ of $p$-hydroxy benzoyl hydrazine was dissolved in $25 \mathrm{ml}$ of distilled water, $1 \mathrm{mmol}$ of DTPAA and $5 \mathrm{ml}$ of pyridine (Py) was placed in the aqueous solution, with stirring for $24 \mathrm{~h}$ at room temperature. $\mathrm{H}_{2} \mathrm{O}$ and $\mathrm{Py}$ were removed under reduced pressure and the residue was diluted with $\mathrm{H}_{2} \mathrm{O}$ and filtered. Then a drop of the solution of $\mathrm{EtOH}^{\mathrm{O}}$ and $\mathrm{Et}_{2} \mathrm{O}(\mathrm{v} / \mathrm{v}=1 / 2)$ added into filtrate, and a large amount of white precipitate separated out. Filter and was washed three times with a little EtOH. Finally, product was dried in a vacuum with $\mathrm{P}_{4} \mathrm{O}_{10}$. Recrystallization from $\mathrm{H}_{2} \mathrm{O}-\mathrm{Et}_{2} \mathrm{O}-\mathrm{EtOH}$ gain the final product. Yield: $89.8 \%$. Melting point: $209-211^{\circ} \mathrm{C}$. ${ }^{1} \mathrm{H}-\mathrm{NMR}(300 \mathrm{MHz}$, DMSO- $\left.d_{6}\right) \delta: 2.93,3.07$ (each $4 \mathrm{H}$, br s, $\left.-\mathrm{NCH}_{2} \mathrm{CH}_{2} \mathrm{~N}-\right), 3.52(10 \mathrm{H}, \mathrm{s},-\mathrm{CO}-$ $\left.\mathrm{CH}_{2}-\mathrm{N}-\right), 7.28(4 \mathrm{H}, \mathrm{d}, J=7.8 \mathrm{~Hz}, \mathrm{Ar}-\mathrm{H}), 7.74(4 \mathrm{H}, \mathrm{d}, J=7.8 \mathrm{~Hz}, \mathrm{Ar}-\mathrm{H})$ $10.24(2 \mathrm{H}, \mathrm{s},-\mathrm{OH})$. IR $(\mathrm{KBr}) \mathrm{cm}^{-1}: 3388,3229,1733,1698,1633,1221$

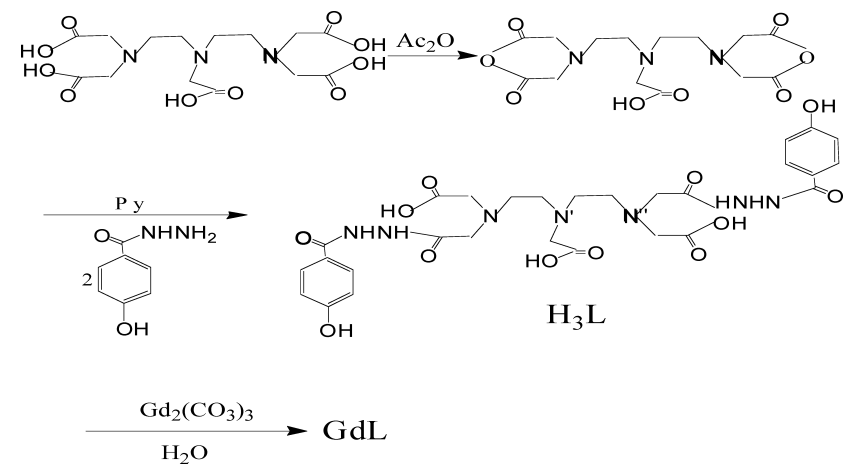

Fig. 1. The Synthetic Routes of the Ligand and the Complex 
FAB-MS: $m / z=662$. Anal. Calcd for $\mathrm{C}_{28} \mathrm{H}_{35} \mathrm{~N}_{7} \mathrm{O}_{12}: \mathrm{C}, 50.38 ; \mathrm{H}, 5.33 ; \mathrm{N}$, 14.82. Found: C, 50.62; H, 5.38; N, 14.80 .

Preparation of Complex First, $1 \mathrm{mmol}$ of $\mathrm{H}_{3} \mathrm{~L}$ was dissolved in $25 \mathrm{ml}$ of distilled water to form a homogeneous solution which $\mathrm{pH}$ is approximately 3 . Then an excess of $\mathrm{Gd}_{2}\left(\mathrm{CO}_{3}\right)_{3}$ was added to the system which was stirred on a water bath until the $\mathrm{pH}$ of the system is approximately 7 . The excess $\mathrm{Gd}_{2}\left(\mathrm{CO}_{3}\right)_{3}$ was filtered off. Then the filtrate was concentrated on a water bath until it is nearly dry. The light yellow powder was then obtained after the mother liquor was removed. Finally, it was dried in vacuum with $\mathrm{P}_{4} \mathrm{O}_{10}$. Yield: $97.6 \%$. IR (KBr) cm $\mathrm{cm}^{-1}: 3218,3186,1618,1550,1398,1215$, 875, 549. Anal. Calcd for $\mathrm{C}_{28} \mathrm{H}_{34} \mathrm{~N}_{7} \mathrm{O}_{13} \mathrm{Gd}$ : C, 40.33; H, 4.11; N, 11.76; Gd, 18.9. Found: $\mathrm{C}, 40.34 ; \mathrm{H}, 4.15 ; \mathrm{N}, 11.79 ; \mathrm{Gd}, 18.2$.

\section{Results and Discussion}

The Composition and General Character of Complex Complex of $\mathrm{Gd}(\mathrm{III}) \mathrm{L}$ is easily soluble in water, DMF and DMSO, and slightly soluble in ethanol, insoluble in acetone, chloroform, and $\mathrm{Et}_{2} \mathrm{O}$, quite stable at room temperature and normal pressure and not sensitive to light. The molar conductivities of $\mathrm{Gd}(\mathrm{III}) \mathrm{L}$ was $10.2 \mathrm{~s} \cdot \mathrm{cm}^{2} \cdot \mathrm{mol}^{-1}$ in $\mathrm{DMF}$, which shows that complex was non-electrolytic nature in DMF, which was composed of metal ions and ligand in a proportion of $1: 1 .^{9)}$

IR Spectra Two new vibrations of $\mathrm{CO}_{2}^{-}$for $v_{\mathrm{as}}$ and $v_{\mathrm{s}}$ appear at 1550 and $1398 \mathrm{~cm}^{-1}$, the $\Delta v\left(v_{\mathrm{as}}-v_{\mathrm{s}}\right)$ of which is equal to $152 \mathrm{~cm}^{-1}$. The IR spectra obtained when the sodium salt of the ligand is used as a control show that its $v_{\text {as }}$ and $v_{\mathrm{s}}$ are at 1550 and $1410 \mathrm{~cm}^{-1}$, respectively, and $\Delta v\left(v_{\mathrm{as}}-v_{\mathrm{s}}\right)$ is $140 \mathrm{~cm}^{-1}$, suggesting that carboxyl oxygen atom coordinated to metal ion with single-dentate. ${ }^{10)}$ The ligand provided three nitrogen atoms, five carboxyl oxygen atoms bonding to metal ion. One water molecule takes part in coordination to metal ion confirming DAT-TG.

Thermal Analyses Ligand shows an endothermic peak at $210^{\circ} \mathrm{C}$, but without mass loss in the TG curve. This fact indicates that it is a process of phase conversion, which is in conformity with the melting point of the ligand. Complex of $\mathrm{GdL}$ has an endothermic peak at $129^{\circ} \mathrm{C}$, which shows that there is coordinating water in complex of $\mathrm{GdL}$, the corresponding TG curve show that the weight loss is equal to a water molecule. The results are in accordance with the composition of the complex as determined by elemental analyses.

Thermodynamic Stability Constant of the Complex The normal chelate of thermodynamic stability constants is expressed as in equation ${ }^{6}$ :

$K=[\mathrm{ML}] /\left[\mathrm{M}^{n+}\right]\left[\mathrm{L}^{n-}\right]$

Where $\mathrm{M}^{n+}$ represents the free, unhydrolysed aqua-metal ion, $\mathrm{L}^{n-}$ the uncomplexed, totally deprotonated from the ligands and ML is the normal unprotonated and unhydrolysed complex. Thermodynamic stability constant of GdL $\left(K_{\mathrm{GdL}}=10^{20.15}\right)$ was a little less than that of $\operatorname{Gd}(\mathrm{DTPA})^{2-}$ $\left(K_{\mathrm{Gd}-\mathrm{DTPA}}=10^{20.73}\right)$.

Relaxivity of the Complex in Water Solution The enhancement value of the relaxation rate of the complex for water protons is calculated by the equation. ${ }^{5)}$

$$
\begin{aligned}
& \left(1 / T_{1}\right)_{\mathrm{p}}=\left(1 / T_{1}\right)_{\mathrm{o}}-\left(1 / T_{1}\right)_{\mathrm{d}} \\
& R_{1}=\left(1 / T_{1}\right)_{\mathrm{p}} /[\mathrm{M}]
\end{aligned}
$$

Where $\left(1 / T_{1}\right)_{0}$ is the observed solvent relaxation rate in the presence of a paramagnetic species, $\left(1 / T_{1}\right)_{\mathrm{d}}$ is the solvent relaxation rate in the absence of a paramagnetic species, and $\left(1 / T_{1}\right)_{\mathrm{p}}$ represents the additional paramagnetic contribution. $[\mathrm{M}]$ is the concentration of paramagnetic metal ion.

The relaxivity mainly consists of two components: the inner-sphere and outer-sphere relaxivity. The high relaxivity is favourable of tissue imaging. The relaxivity $\left(R_{1}\right)$ of Gd(III)L and Gd(DTPA) ${ }^{2-}$ used as a control were given in Table 1. The results showed that the spin-lattice relaxivity of $\mathrm{GdL}^{1}$ was larger than that of $\mathrm{Gd}(\mathrm{DTPA})^{2-}$. Measurement of relaxation time of GdL was showed in Fig. 2.

Relaxivity of the Complex in HSA Solution HSA is one the most important plasma proteins involved in drag delivery in the body. The albumin concentration in human plasma is close to $0.6 \mathrm{mmol} / \mathrm{l}^{11)}$ For the application in MRI, it may be useful to study the relaxation rates of the complex at the physiological concentration of HSA.

In Fig. 3 we report the behaviour of the longitudinal relaxation rates of water protons on increasing the concentration of GdL $(0-5 \mathrm{mmol} / \mathrm{l})$ in $0.6 \mathrm{mmol} / 1 \mathrm{HSA}$ solution. The relaxivity $\left(R_{1}\right)$ of $\mathrm{Gd}(\mathrm{III}) \mathrm{L}$ of complex was $7.691 \cdot \mathrm{mmol}^{-1} \cdot \mathrm{s}^{-1}$ which was larger than that of in water solution $\left(R_{1}=\right.$ $\left.6.391 \cdot \mathrm{mmol}^{-1} \cdot \mathrm{s}^{-1}\right)$. The results showed that $\mathrm{Gd}(\mathrm{III}) \mathrm{L}$ of complex displays a binding affinity for the serum protein.

Table 1. Relaxivity of the Complex

\begin{tabular}{lcccccc}
\hline \hline Compounds & $\begin{array}{c}{[\mathrm{M}] /} \\
\mathrm{mmol} \cdot 1^{-1}\end{array}$ & $t_{0} / \mathrm{s}$ & $T_{1} / \mathrm{s}$ & $\left(1 / T_{1}\right)_{\mathrm{p}} / \mathrm{s}^{-1}$ & $\begin{array}{c}R_{1} / \\
\mathrm{mmol} \cdot 1 \cdot \mathrm{s}^{-1}\end{array}$ & Temp. $/{ }^{\circ} \mathrm{C}$ \\
\hline $\mathrm{H}_{2} \mathrm{O}+\mathrm{D}_{2} \mathrm{O}$ & & 5.40 & 0.128 & & & 35 \\
$\mathrm{GdL} \cdot \mathrm{H}_{2} \mathrm{O}$ & 0.094 & 0.95 & 0.729 & 0.601 & 6.39 & 35 \\
$\mathrm{Gd}-\mathrm{DTPA}$ & 0.148 & 0.90 & 0.770 & 0.642 & 4.34 & 35
\end{tabular}

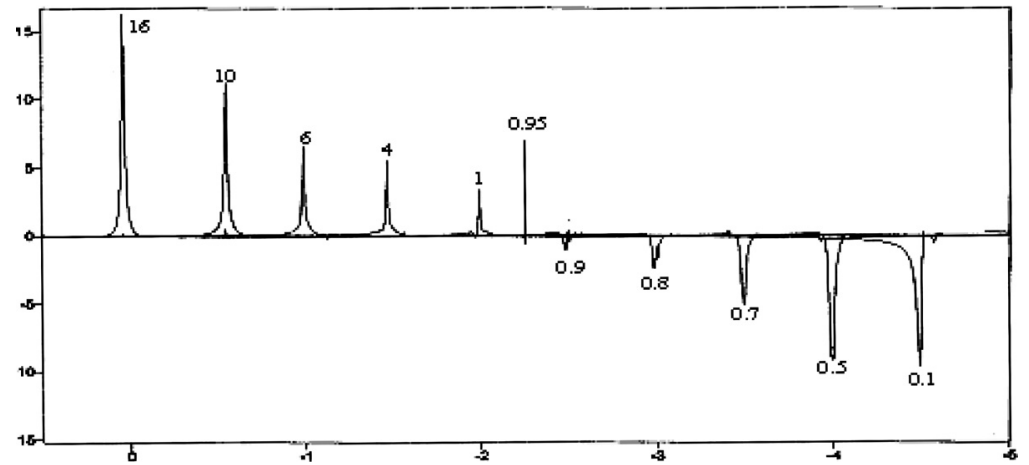

Fig. 2. Measurement of Relaxation Time of GdL 


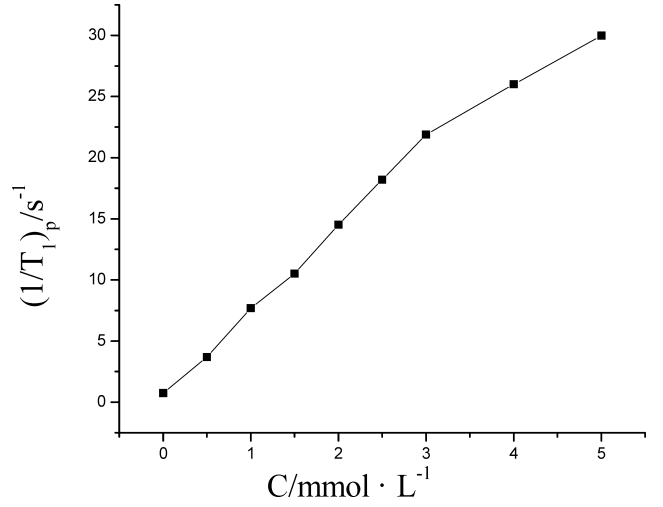

Fig. 3. The Longitudinal Relaxation Rates of Water Protons in $0.6 \mathrm{mmol}$ HAS Solution on Increasing the Concentration of GdL $(0-5 \mathrm{mmol} / \mathrm{l})$

Taken together, neutral Gd(III) complexe derivative from diethylene triamine pentaacetic acid and $p$-hydroxy benzoyl hydrazine is prospective MRI contrast agent with high spinlattice relaxivity and stability, low cost, good solubility and binding affinity for the serum protein.

Acknowledgements Project supported by the National Natural Science Foundation (20475023) and Gansu NSF (3ZS04-A25-016).

\section{References}

1) Caravan P., Ellison J. J., McMurry T. J., Lauffer R. B., Chem. Rev., 99, 2293-2352 (1999).

2) Weinmann H. J., Brash R. C., Press W. R., Am. J. Roentgenol., 142 , 619-622 (1984).

3) Chang C. A., Invest. Radiol., 28 (Suppl. 1), 22-25 (1993).

4) MarK S. K., William C. D., David B. L., Kenneth N. R., Steven C. Q., Scott M. R., Inorg. Chem., 29, 1488-1491 (1999).

5) Yang Z. Y., Li F. S., Yang L., Yang R. D., Chinese Science Bull., 20, 1844-1850 (2000).

6) Rizkalla E. N., Choppin G. R., Inorg. Chem., 25, 2327-2330 (1986).

7) Geigy J. R., Fr. Patent, 1, 548, 888 (1987).

8) Hnatowich D. J., Layne W. W., Childs R. L., Int. J. Appl. Radiat. Isot., 33, 327-332 (1982).

9) Geary W. J., Cood. Chem. Rev., 7, 81—92 (1971).

10) Nakamoto K., "Infrared and Raman Spectra Inorganci and Coordination Compounds," Chap. 3, John Wiley, New York, 1976.

11) Silvio A., Monica C., Giuseppe D., Eliana G., Enzo T., J. Bio. Inorg. Chem., 4, 766-774 (1999). 